\title{
Е.К. Маслова
}

\section{СРАВНИТЕЛЬНЫЙ АНАЛИЗ МЕТОДОЛОГИЧЕСКИХ ПОДХОДОВ СОЦИОЕСТЕСТВЕННОЙ ИСТОРИИ НА ПРИМЕРЕ Э.С. КУЛЬПИНА И Л.Н. ГУМИЛЕВА}

\begin{abstract}
Развитие современной науки в сторону междисциплинарности ставит проблему релевантности использования нетрадиционных для гуманитарного познания методологий. Рассматриваются два подхода авторов, использующих междисциплинарные методы: Л.Н. Гумилева, чьи взгляды подвергаются критике по критериям научности с момента первых его публикаций, и Э.С. Кульпина, который создал новое направление научных исследований, назвав его «социоестественная история» и противопоставив «традиционной истории». Выбор именно этих авторов обусловлен их схожестью в концепциях и методологии акцент ставится на природные факторы в истории, методология опирается на междисциплинарность. В то же время реакция научного сообщества на их творчество сильно разнится.

Ключевые слова: социоестественная история; Э.С. Кульпин; Л.Н. Гумилев; междисциплинарность.
\end{abstract}

Междисциплинарные подходы становятся все более актуальными в современной гуманитарной науке, они находят отражение не только в работах историков, но даже в создании научных школ, как, например, школы социоестественной истории, основным принципом которой является изучение истории человечества неотрывно от истории природы. Социоестественная история (СЕИ) опирается на традиционную историю, она и есть прежде всего история, предмет, назначение которого - изучение взаимосвязей и взаимозависимости явлений, процессов и событий в жизни людей и в жизни природы как в настоящем, так и в прошлом [1. C. 17]. Наиболее известным представителем российской социоестественной истории является Эдуард Сальманович Кульпин - кандидат экономических наук, доктор философских наук, профессор, главный научный сотрудник Института социологии и Института востоковедения РАН, заведующий кафедрой истории Московского физико-технического института.

СЕИ как наука сформировалась относительно недавно. Связи между обществом и природой ученые называют социоестественными, так как в этом названии отражена взаимозависимость человека и природы, а также подчеркивается междисциплинарность как основное условие изучения. СЕИ возникла вследствие необходимости разрешить те вопросы, на которые не удалось найти ответ в рамках традиционных научных дисциплин, не отказываясь от прежнего знания, а только добавив новое.

Изучить историю природы совместно с историей человечества пытался и Л.Н. Гумилев. В созданной им теории этногенеза также использовалась методология разных научных дисциплин, что позволило поставить иные вопросы и, соответственно, дать на них иные, нетипичные для исторической науки ответы.

Однако реакция научного сообщества на эти два подхода существенно разнится: Гумилева часто обвиняют в ненаучности его идей, в недоказуемости выводов, а СЕИ воспринимается вполне толерантно. Почему же одна из теорий оказывается по факту выведена за «рамки научности», а другая воспринимается вполне толерантно в российской и зарубежной науке - ответов на эти вопросы нет, хотя историография теории Л.Н. Гумилева представлена в большом объеме. Его концепция этногенеза относится к числу наиболее спорных теорий, вызывающих широкий, не всегда научный интерес. Резко негативно к Гумилеву относится Юлиан Бромлей. Полемика Л.Н. Гумилева с Ю.В. Бромлеем продолжалась долгие годы. Суть спора коренилась в отношении к природе этноса. Бромлей обвинял Гумилева в излишнем биологизаторстве, не принимал его теорию химер. Решительно не согласны с концепцией Гумилева Б. Кедров, И. Григулевич и И. Крывелёв. Отрицает научные достижения Гумилева В.А. Шнирельман.

Однако наряду с авторами, отрицающими научность идей Гумилева, есть большое число и тех, кто считает себя приверженцем этих теорий. Так, например, абсолютным приверженцем концепции Л.Н. Гумилева является Ю.М. Бородай. В первую очередь, Бородай доказывает, что теория этногенеза - сугубо марксистская, что, в свою очередь, оспаривают некоторые его оппоненты. Подробно анализировали работы Гумилева также Г.С. Померанц, Л. Клейн, М.И. Чемерисская.

Историография СЕИ в основном внутренняя, у социоестественников хорошо развита рефлексия. Например, Т.Ф. Столярова весьма подробно разбирает социоестественную историю с точки зрения мировоззренческой парадигмы. Исследует СЕИ и сам Э.С. Кульпин. Поскольку школа СЕИ - современный феномен, еще не формализованный, официальных и неофициальных рецензий не выходило, а обширной историографии еще не сложилось.

Для того чтобы разобраться в поставленной проблеме, нужно сравнить практическое применение методов данных теорий.

Основным методом исследования в СЕИ является междисциплинарность. И в первую очередь это не означает прямого перенесения методов исследования из естественных наук, изучающих живую и неживую природу, в область гуманитарных наук, изучающих 
общество - гораздо более сложную систему. Наоборот, на основании естественнонаучных подходов разрабатывается новая методология.

Серьезным отличием Гумилева от СЕИ является то, что в СЕИ четко прописана и проработана методология, это позволяет избежать механического соединения множества отдельных факторов (географических, биологических и т.п.). На это указывает Т.Ф. Столярова в докладе на III конференции «Человек и природа. Проблемы социоестественной истории» [2]. В частности, прописано особое значение использования методологии и данных естественных наук: используются характеристики климатических зон, точные географические измерения, уровень воды мирового океана, градусы температур и т.п. Например, в книге «Золотая Орда: проблемы генезиса Российского государства» приводятся данные максимальных значений температур во время распада Золотой Орды: в Причерноморье -6 градусов по Цельсию, против -35 градусов в Восточном Казахстане, а также длительность безморозного периода (260 дней против 193) и сумму годовых осадков (330 мм против 235) [3. С. 92].

Большинство из подобных методов использует и Л.Н. Гумилев: «Изучая этногенез, исследователь применяет методы географии» [4. С. 178-179]. Так, например, при изучении истории Хазарии он большое внимание уделяет уровню Каспийского моря в разные исторические периоды. По его данным, в ХХ в. этот уровень состоял на отметке минус 28 м, в Х в. - на отметке минус 28,5-29,5 м [5. С. 27]. Гумилев говорит, что это практически современный уровень или немного ниже [Там же. С. 93].

Э.С. Кульпин выделяет типичную ошибку гуманитариев - в отличие от естественников, они, не имея исчерпывающих данных, но приводя колоссальное количество фактов, не делают на основании их обобщения [6] Он не отрицает тот факт, что Гумилев это обобщение использовал в гуманитарной сфере, но использовал эмпирическое обобщение - новый реальный факт, обнаруженный не прямым, а косвенным наблюдением [Там же]. Эмпирическое обобщение используется и в СЕИ.

Помимо этого, одним из главных принципов анализа в СЕИ является принцип дополнительности, который сформулирован так: «Одно и то же событие мы можем охватить с помощью двух различных способов рассмотрения. Оба способа взаимно исключают друг друга, но также дополняют друг друг, и лишь сопряжение двух противоречащих друг друга способов рассмотрения полностью исчерпывает наглядную суть явлений» [Там же]. Принцип разработан физиками Н. Бором, Б. Паули и В. Гейзенбергом. Но Кульпин не просто копирует метод, он перерабатывает его под свой предмет исследования: в анализе, с одной стороны, используются закономерности из истории людей, а с другой - истории природы.

В отличие от Л.Н. Гумилева, который в качестве основного вида доказательства использует приведение всевозможных фактов, Кульпин считает, что принцип, принятый у гуманитариев, - приведение большого количества фактов и остановка перед выведением общего правила до тех пор, пока накопленное количество фактов не покажет их всеобщность, - не рационален [Там же].

Исходя из значимости свидетельств естественных наук, СЕИ не изучает поступки отдельной личности, в отличие от Гумилева, который считал, что личность способна влиять на ход истории. Но социоестественники не отрицают факт такого влияния, они просто не считают это предметом своего изучения, поскольку поступки отдельного человека не выявляют глобальной взаимосвязи между обществом и природой. Однако в сентябре 2010 г. и марте 2011 г. в журнале «История и современность» под редакцией Кульпина в разделе «Теоретические проблемы истории» были опубликованы две статьи Л.Е. Гринина: «Личность в истории: эволюция взглядов» [7. С. 3-44] и «Личность в истории: современные подходы» [8. С. 3-41]. В данных статьях доказывается, что в век глобализации есть серьезная необходимость уделить внимание исследованию этой проблемы. Конечно, в журнале есть сноска, сообщающая о том, что публикуемые материалы могут не отражать точку зрения учредителя и редакции [9. С. 2], однако редакция самостоятельно отбирает актуальные и подходящие под тематику ${ }^{1}$ журнала статьи. Это характеризует редактора, Э.С. Кульпина, как толерантного к любому виду научного знания, если оно помогает открыть новые методы, показать лакуны уже имеющихся знаний и позволяет дать прирост новых.

Еще одним методом СЕИ является составление синхронистической таблицы. Разумеется, синхронистическая таблица не может заменить текста, в котором события изложены подробно, а связи между ними обоснованы. Но таблица на это и не претендует; она лишь дополняет текст и служит фундаментом. Синхронистическая таблица выявляет значимость процессов, а значит, и направления - объекты конкретных исследований. Она же показывает «узкие места» - те, где известных фактов для понимания процессов недостаточно и необходимо либо дополнительное специальное исследование, либо, если таковое невозможно, искусственная реконструкция - моделирование. В сборниках СЕИ [10. С. 269] всегда печатаются синхронические таблицы, есть они и в книгах Гумилева [11. С. 467-506]. Однако Гумилев синхронизирует процессы в жизни этноса с процессом нарастанияугасания пассионарности, тогда как Кульпин - процессы в жизни общества и природы.

Как видно из таблиц, Э.С. Кульпин заносит в таблицу огромные временные отрезки. Это особая макроистория, иная, чем в марксизме, из-под рамок которого вышел Кульпин. У Л.Н. Гумилева более традиционная для марксизма периодизация, принятая в исторической науке длительное время: эллинизм, Рим и т.д. К тому же Кульпин делает акцент на археологическую периодизацию: неолит, энеолит и т.д., а Гумилев ставит в 
центре исследования этнос, и именно поэтому его таблица построена по культурно-историческим общностям, тогда как Кульпин не разделяет культуры, основа его таблиц - типология событий.

В таблице Л.Н. Гумилева в основном упор делается на политические события, природный фактор представлен гораздо меньше: увлажнение-усыхание, кли- матический оптимум и уровень моря, плюс он относит к климатическому фактору пассионарный толчок (табл. 1). В таблице Э.С. Кульпина есть и климатический оптимум, и похолодание, и смена гидрорежима, и эрозия почв, и влажность, и температура, но большее внимание уделяется экологическому кризису (табл. 2).

Пример синхронистической таблицы из книги Л.Н. Гумилева [12. С. 289]

\begin{tabular}{|c|c|c|c|c|c|}
\hline $\begin{array}{c}\text { Дата } \\
\text { до н.э. }\end{array}$ & Рим & Эллинизм & Туран & Хунну и хань & Природные условия \\
\hline 1 & 2 & 3 & 4 & 5 & 6 \\
\hline $230-221$ & $\begin{array}{c}\text { Покорение италий- } \\
\text { ских галлов }\end{array}$ & Великая Сирия & $\begin{array}{c}\text { Парфяне против } \\
\text { греков }\end{array}$ & $\begin{array}{c}\text { Ослабление хуннов; преобла- } \\
\text { дание дунху. Победа Цинь }\end{array}$ & $\begin{array}{c}\text { Повышенное } \\
\text { увлажнение степи }\end{array}$ \\
\hline $220-210$ & Ганибал в Италии & $\begin{array}{c}\text { Отделение Греко- } \\
\text { Бактрии от Сирии }\end{array}$ & $\begin{array}{c}\text { Гегемония согдов } \\
\text { в Восточной Азии }\end{array}$ & $\begin{array}{c}\text { Завоевание Ордоса и строи- } \\
\text { тельство Великой стены } \\
\text { китайцами }\end{array}$ & $\begin{array}{c}\text { Климатический опти- } \\
\text { мум, пассионарный } \\
\text { толчок }\end{array}$ \\
\hline $209-200$ & $\begin{array}{c}\text { Победа Рима над } \\
\text { Карфагеном }\end{array}$ & $\begin{array}{c}\text { Антиох оттеснил парфян } \\
\text { из Мидии и осадил } \\
\text { Бактры }\end{array}$ & $\begin{array}{c}\text { Поражение хуннов: } \\
\text { жестокая война } \\
\text { усуней и согдов } \\
\text { с хуннами }\end{array}$ & $\begin{array}{c}\text { Модэ организовал державу } \\
\text { Хунну. Покорение соседей. } \\
\text { Провозглашение } \\
\text { Хань империей }\end{array}$ & $\begin{array}{c}\text { Низкий уровень } \\
\text { Каспия (абс. отм. } \\
\text { минус } 32 \text { м) }\end{array}$ \\
\hline
\end{tabular}

Отрывок таблицы СЕИ из книги Э.С. Кульпина [10. С. 256-269]

\begin{tabular}{|c|c|c|c|c|c|}
\hline \multicolumn{2}{|c|}{ Природные } & \multicolumn{2}{|c|}{ Социоестественные } & \multicolumn{2}{|c|}{$\begin{array}{c}\text { Социальные, экономические, политические } \\
\text { и культурные }\end{array}$} \\
\hline \multicolumn{6}{|c|}{ IV-III тыс. до н. э. - мифический «золотой век» } \\
\hline Процессы & $\begin{array}{c}\text { Явления } \\
\text { и события }\end{array}$ & Процессы & $\begin{array}{c}\text { Явления } \\
\text { и события } \\
\end{array}$ & Процессы & Явления и события \\
\hline $\begin{array}{l}\text { Климатический опти- } \\
\text { мум голоцена. На } \\
\text { Средне-Китайской рав- } \\
\text { нине - устойчивый } \\
\text { теплый и влажный кли- } \\
\text { мат, флора и фауна } \\
\text { субтропиков и тропиков }\end{array}$ & $\begin{array}{l}\text { Климатический } \\
\text { оптимум голоцена }\end{array}$ & $\begin{array}{l}\text { Неолит и энеолит. } \\
\text { Переход от охоты, } \\
\text { рыболовства и соби- } \\
\text { рательства к мотыж- } \\
\text { ному земледелию на } \\
\text { аллювиальных и лес- } \\
\text { совых почвах верхне- } \\
\text { го и среднего течения } \\
\text { Хуанхэ }\end{array}$ & & $\begin{array}{l}\text { Первые поселения на } \\
\text { территории Китая. Произ- } \\
\text { водство керамических } \\
\text { сосудов }\end{array}$ & $\begin{array}{l}\text { Возникновение косми- } \\
\text { ческих мифов }\end{array}$ \\
\hline \multicolumn{6}{|c|}{ II тыс. до н. э. - эпоха бронзы } \\
\hline $\begin{array}{l}\text { Медленное похолодание } \\
\text { и аридизация климата с } \\
\text { соответствующей сме- } \\
\text { ной биоты }\end{array}$ & $\begin{array}{l}\text { Резкое похолода- } \\
\text { ние к концу тыся- } \\
\text { челетия, сокраще- } \\
\text { ние вегетационно- } \\
\text { го периода }\end{array}$ & & $\begin{array}{l}\text { Сокращение } \\
\text { массы приба- } \\
\text { вочного про- } \\
\text { дукта }\end{array}$ & $\begin{array}{l}\text { Формирование первых } \\
\text { протогосударств с пись- } \\
\text { менной историей. Сложе- } \\
\text { ние конструктивных ос- } \\
\text { нов деревянной архитек- } \\
\text { туры. Культ предков. } \\
\text { Культ неба }\end{array}$ & $\begin{array}{l}\text { Государство Шан-Инь } \\
\text { (ок. XVI в.). Создание } \\
\text { Шуцзин - книги преда- } \\
\text { ний (ок. XIV-VIII вв.). } \\
\text { Политический кризис, } \\
\text { падение Шан-Инь, воз- } \\
\text { никновение государства } \\
\text { Чжоу (XI в.) }\end{array}$ \\
\hline
\end{tabular}

Если провести параллели между двумя таблицами, то можно увидеть, что у авторов есть пересечения в рассмотрении природных процессов: оба рассматривают в качестве таковых климатический оптимум, а также аридизацию/гумидизацию. Однако Гумилев не выходит дальше, не выстраивает события и процессы в области совместной деятельности человека и природы, что делает Кульпин.

Вновь обратимся к статье М.А. Бойцова, который говорил, что генерализирующие исследования становятся неактуальными в науке [13. С. 17-41]. Его критики (А.Я. Гуревич, И.С. Свенцицкая) писали о том, что нельзя рассматривать часть без представления о целом [14]. Но дробление предметов изучения на все более и более узконаправленные приводит к тому, что специалист становится менее сведущ в изучении целого. По- этому, чтобы составить генерализирующую картину, СЕИ привлекает разных специалистов, чтобы как раз и собрать из частей - целое. Тем более что междисциплинарное исследование требует знаний в разных отраслях науки. Если всеми нужными знаниями обладает исследователь, тогда он может один решить задачу. Такой вариант не правило, а исключение, с точки зрения Э.С. Кульпина.

Гумилев являет собой упомянутое исключение, он сам пытался быть специалистом сразу во всем, что и затрудняло его работу, а также оценку его работ. А. Савченко пишет, что познания Гумилева были энциклопедическими, а память феноменальная, причем не только в истории, но и во многих других науках, в поэзии и даже в религиозной догматике [15. C. 24]. 
Социоестественное исследование же является комплексным и, как правило, требует коллектива разных специалистов. Задачу может поставить любой член коллектива, но руководитель или все участники коллектива должны определить, что требуется для решения задачи. Этот метод Кульпин называет методом «Апполо», т.е. делаться все должно подобно программе «Апполон» - высадке человека на Луне. Поэтапно выясняется, какие проблемы должны быть решены, чтобы была выполнена поставленная задача. Далее, что нужно сделать для решения проблем, - это выявить проблемы первого и второго ярусов. Затем, если необхо- димо, - третьего и дальнейшего ярусов. Так определяется круг проблем, а следовательно, и круг специалистов, порядок работы. Это позволяет привлекать узких специалистов для создания единой концепции, а следовательно, минимизировать риски ошибок из-за недостаточности знаний ученого в какой-либо из областей.

Графики и схемы в книгах СЕИ, в отличие от некоторых графиков у Гумилева, содержат необходимые для анализа данные. В книге Д.Б. Прусакова «Древний Египет: почва цивилизации» представлен график аномалий среднегодовой температуры Северного полушария в голоцене по В.В. Клименко [16. С. 26] (рис. 1).

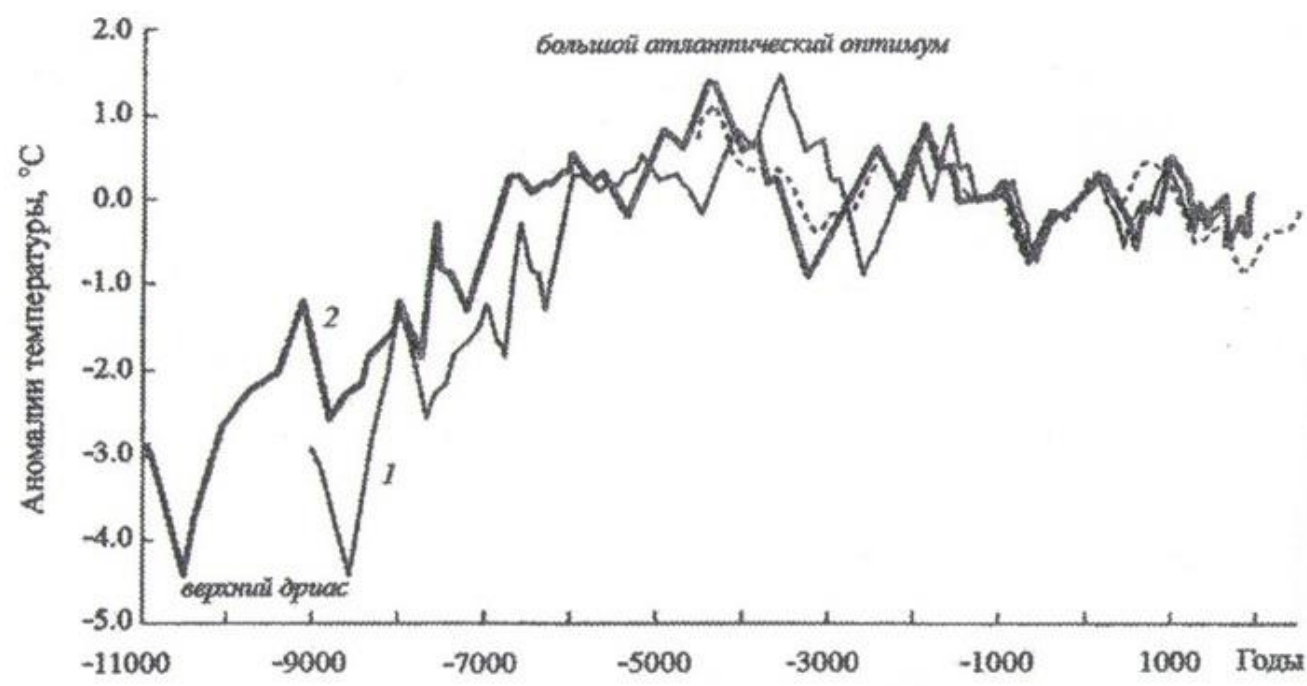

Рис. 1. График аномалий среднегодовой температуры Северного полушария в голоцене по В.В. Клименко

В отличие от графиков из книги Л.Н. Гумилева, на этом графике по осям отложены измеримые величины: на оси абсцисс - время в годах, на оси ординат - температуры в градусах по Цельсию.

Кривые построены исходя из вычисленных обозначений: 1 - радиоуглеродные даты, 2 - календарные да- ты. Показательно, что Прусаков, будучи доктором исторических наук, не берется самостоятельно простраивать график аномалий температур, а берет его у В.В. Клименко - доктора технических наук. Для сравнения - один из самых спорных графиков Гумилева (рис. 2).

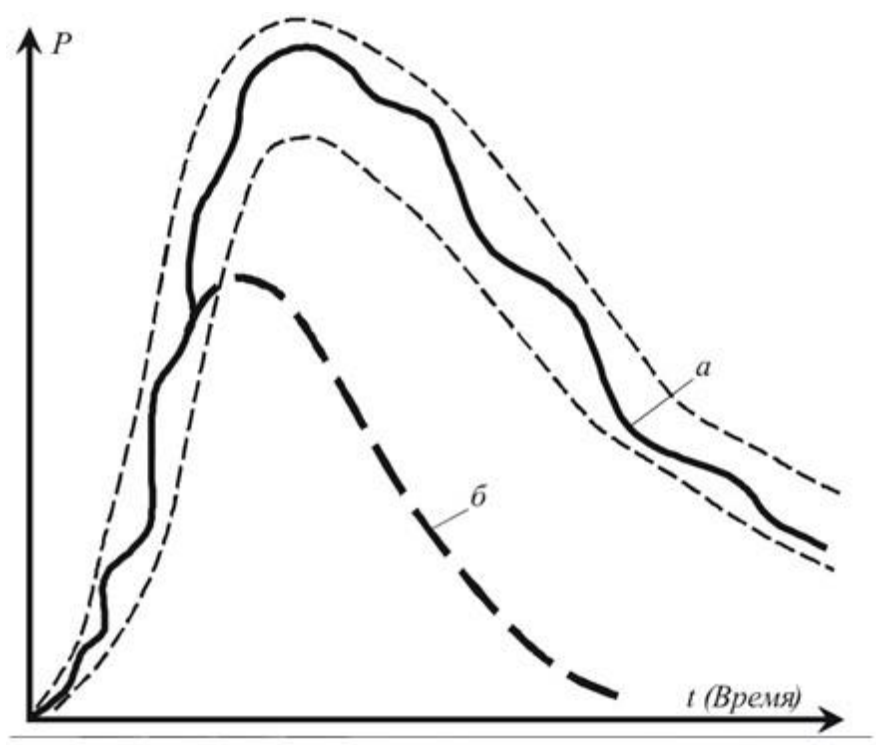

Рис. 2. Идеализированный ход функции Р, характеризующий ход процесса этногенеза 
Использование Л.Н. Гумилевым терминов из неисторических сфер часто критиковалось его оппонентами. Применяя термины естественных наук («излучение», «аннигиляция», «импульс инстинкта», «индукция»), он превращал социокультурные явления в явления физические. Напротив, Э.С. Кульпин пишет, что понятия пограничных научных дисциплин могут использоваться только в тех случаях, когда возникает необходимость в более точных (узких) дефинициях, если же такой необходимости нет, «социоестественник должен руководствоваться принципом: не создавать без нужны новые сущности» [6]. Обычно новая научная дисциплина влечет за собой появление нового научного языка, но междисциплинарность порождает особую проблему. Необходимость сохранения языка наук, на стыке которых рождается новая, усложняется необходимостью овладения терминологиями таких далеких друг от друга гуманитарных и естественных наук.

Основные термины СЕИ, например бифуркация, суперэтнос, цивилизация, социально-экологический кризис и т.д., общеизвестны и также употребляются Львом Гумилевым. Естественнонаучные термины, действительно, используются редко и в необходимом контексте, например: «динамика показывает стабильность условий климатического оптимума» [17. С. 44] или «соотношение сил факторов “выталкивания-притяжения” <..> показывают, что не только внутренние пружины развития этноса $\langle\ldots>$, но и внешние обусловили массовое переселение» [Там же. С. 52]. Сам язык написания работ Кульпина сложно назвать завораживающим, в отличие от стиля языка Л.Н. Гумилева, однако содержательность и информативность текста не отменяют его стилистическую красоту и читательский интерес. Отсутствие шокирующих метафор не будет лишний раз смущать критиков и ставить под сомнение научность текста, что как раз и случилось с работами Гумилева.
В целом сложно сказать, что методология СЕИ является новой в науке, она признана во многих областях знаний (например, принцип дополнительности используется в квантовой механике), однако для исторических исследований она еще не применялась в таком масштабе. Но и непризнанными методами истории это назвать нельзя: можно встретить подобное в археологии или социальной антропологии, однако не всегда в качестве основных методологических установок. Еще в 1920-е гг. была разработана программа функционального исследования археологического материала с применением методов естественных наук, большое значение стали придавать показаниям четвертичной геологии и палеоботаники [18. С. 38]. А при анализе результатов процесса раскалывания галечных форм археологом П.В. Волковым была использована типология, основанная на принципе, который можно было бы назвать тригонометрическим: типология галечных артефактов основывалась на восприятии процесса первичного расщепления как процесса деления эллипсоидных форм на абстрактные доли, сектора и прочие части геометрической фигуры [19. С. 9].

И Гумилев, и Кульпин стремились находить новые объяснения старых и нерешенных проблем в рамках междисциплинарного исследования. Однако используемые методы, которые Гумилев приписывает к естественнонаучным, не всегда таковыми являются. Критики находят вольно простроенные таблицы и графики, а термины из других научных дисциплин не всегда оправданы и приспособлены для гуманитарного исследования. Но это лишь еще одна «зацепка» против научности теории Гумилева, тогда как кардинальной разницы в методологиях СЕИ и Гумилева не наблюдается (скорее, в их применении). Следовательно, существенное основание для разведения данных двух теорий следует искать в другом поле.

\section{ПРИМЕЧАНИЕ}

\footnotetext{
${ }^{1}$ Основные темы журнала «История и современность»: история цивилизаций и народов, теоретические проблемы истории, основные проблемы современности, связь общества и природы.
}

\section{ЛИТЕРАТУРА}

1. Прусаков Д.Б. Природа и человек в Древнем Египте. М. : Московский лицей, 1999. 240 с.

2. Столярова T.Ф. Социоестественная история как одно из оснований мировоззренческой парадигмы XXI века. URL: http://www.kulpin.ru/?page id=471, свободный (дата обращения: 26.09.2012).

3. Кульпин Э.С. Золотая Орда: проблемы генезиса Российского государства. Изд. 2-е, испр. М. : КомКнига, 2006.176 с.

4. Гумилев Л.Н. Этногенез и биосфера Земли. М. : АСТ, 2002. 560 с.

5. Гумилев Л.Н. Открытие Хазарии. М. : Айрис-пресс Рольф, 2001. 411 с.

6. Кульпин Э.С. Бифуркация Запад - Восток. Введение в социоестественную историю. URL: http://www.kulpin.ru/?page_id=101, 20012, cвободный (дата обращения: 27.02.12).

7. Гринин Л.Е. Личность в истории: эволюция взглядов // История и современность. 2010. № 2.

8. Гринин Л.Е. Личность в истории: современные подходы // История и современность. 2011. № 1 (13)

9. История и современность. 2011. №1 (13).

10. Кульпин Э.С. Восток. Человек и природа на Дальнем Востоке. (Серия «Социоестественная история. Генезис кризисов природы и общества в России» / под ред. Э.С. Кульпина. Вып. ХІІ). М. : Московский лицей, 1998. 272 с.

11. Гумилев Л.Н. Древняя Русь и Великая Степь. М. : Товарищество Клышников, Комаров и Ко, 1992.520 с.

12. Гумилев Л.Н. Тысячелетие вокруг Каспия. М. : Айрис-пресс, 2003. 384 с.

13. Бойцов М.А. Вперед, к Геродоту! // Казус. Индивидуальное и уникальное в истории. М. : Изд-во РГГУ, 1999. С. 17-41.

14. Есть ли будущее у науки о прошлом? (дискуссия по поводу статьи M. Бойцова «Вперед, к Геродоту!»). 1999. URL: http://archive.svoboda.org/programs/td/1999/td.030399.asp, свободный (дата обращения: 25.03.2015). 
15. Савченко А. Семь лет рядом со Львом Гумилевым // Новый мир. 1996. № 2. С. 240-250.

16. Прусаков Д.Б. Древний Египет: почва цивилизации (Этюд о неолитической революции) / отв. ред. Э.С. Кульпин. М. : Книжный дом «ЛИБРОКОМ», 2010. $152 \mathrm{c}$.

17. Кульпин Э.С. Русь между Западом и Востоком. Серия «Социоестественная история. Генезис кризисов природы и общества в России». Вып. XVIII. М. : Институт востоковедения РАН, 2001. 232 с.

18. Викторова В.Д. Научный поиск в археологии. Свердловск : Изд-во Урал. ун-та, 1989. 152 с.

19. Волков П.В. Методика технологического исследования и типологии галечных артефактов : учеб.-метод. пособие. Новосибирск : Новосибирский гос. ун-т, Институт археологии и этнографии СО РАН, 2009. 76 с.

Maslova Ekaterina K. Tomsk State University (Tomsk, Russia). E-mail: ekaterina_maslova@sibmail.com

COMPARATIVE ANALYSIS OF METHODOLOGICAL APPROACHES SOCIAL-NATURAL HISTORY (THE CASE OF E.S. KULPIN) AND L.N. GUMILEV.

Keywords: social-natural history; E.S. Kulpin; L.N. Gumilev; interdisciplinary.

The development of modern science toward interdisciplinary puts a problem of relevance of using unconventional methodologies for humanitarian knowledge. This article considers two authors using interdisciplinary methods: L.N. Gumilev, whose views have been criticized by scientific criterions since his first publications, and E.S. Kulpin, who created the new direction of scientific researches called "Social-natural history" and who opposed that to «traditional history». The choice of these authors is caused by their similarity in conceptions and methodology - the accent is put on natural factors in history, the methodology bases on interdisciplinarity. At the same time the reaction of scientific community to their studies widely varies. Why is one of the theories in fact is beyond the "scope of science" and the other theory is perceived quite tolerantly? The answer to a question is not found in the Russian and foreign science, although the historiography of the theory of L.N. Gumilev is presented in large volume. We will try to answer this question, using comparative analysis of methodological approaches of both theories. The interdisciplinary research requires knowledges in the different branches of sciense. The researcher can solve the problem by himself, if he has all necessary knowleges. According to E.S. Kulpin this variant is not rule, but the exception. Gumilev is an exception, he tried to be an expert in everything that made his work and an assessment of his papers difficult. The Social-natural research is complex and usually requires a team of different specialists. Any member of the team can set the task, but the head or all team members must determine what is needed to solve the problem. It is difficult to say that the methodology of Social-natural history is new in science, it is recognized in many areas of knowledges (for example, the principle of a complementarity which is used in quantum mechanics), but it was not applied for historical researches in such numbers yet. Also it is difficult to call the methodology of Social-natural history unrecognized methods of history: it can met in archeology or in social anthropology, but not always as the main methods. L.N. Gumilev and E.S. Kulpin tried to find a new explanations of old and unsolved problems in interdisciplinary research. However, the methods which L.N. Gumilev attributes to the natural sciences, not always those are. Critics find freely created tables and schedules, and terms of other scientific disciplines are not always justified and adapted for humanitarian research.

\section{REFERENCES}

1. Prusakov, D.B. (1999) Priroda i chelovek v Drevnem Egipte [Nature and Man in Ancient Egypt]. Moscow: Moskovskiy litsey.

2. Stolyarova, T.F. (1994) Sotsioestestvennaya istoriya kak odno iz osnovaniy mirovozzrencheskoy paradigmy XXI veka [Sotsionatural history as one of the foundations of a world outlook paradigm of the 21st century]. [Online] Available from: http://www.kulpin.ru/?page_id=471. (Accessed: 26th September 2012).

3. Kul'pin, E.S. (2006) Zolotaya Orda: problemy genezisa Rossiyskogo gosudarstva [The Golden Horde: The genesis of the Russian state]. 2nd ed. Moscow: KomKniga.

4. Gumilev, L.N. (2002) Etnogenez i biosfera Zemli [Ethnogenesis and biosphere of the Earth]. Moscow: AST.

5. Gumilev, L.N. (2001) Otkrytie Khazarii [Opening of the Khazars]. Moscow: Ayris-press Rol'f.

6. Kul'pin, E.S. (1996) Bifurkatsiya Zapad-Vostok. Vvedenie v sotsioestestvennuyu istoriyu [The West-East Bifurcation. Introduction to the SocialNatural history]. [Online] Available from: http://www.kulpin.ru/?page id=101, 20012. (Accessed: 27th February 2012)

7. Grinin, L.E. (2010) Lichnost' v istorii: evolyutsiya vzglyadov [Personality in History: Evolution of opinions]. Istoriya $i$ sovremennost'. 2.

8. Grinin, L.E. (2011) Lichnost' v istorii: sovremennye podkhody [Person in History: Modern approaches]. Istoriya i sovremennost'. 1(13).

9. Kul'pin-Gubaydullin, E.S. (ed.) (2011) Istoriya i sovremennost'. 1(13).

10. Kul'pin, E.S. (1998) Vostok. Chelovek i priroda na Dal'nem Vostoke [East. Man and Nature in the Far East]. Moscow: Moskovskiy litsey.

11. Gumilev, L.N. (1992) Drevnyaya Rus'i Velikaya Step' [Ancient Rus and the Great Steppe]. Moscow: Tovarishchestvo Klyshnikov, Komarov i Ko.

12. Gumilev, L.N. (2003) Tysyacheletie vokrug Kaspiya [Millennium around the Caspian Sea]. Moscow: Ayris-press.

13. Boytsov, M.A. (1999) Vpered, k Gerodotu! [Ahead, to Herodotus!]. In: Bessmertnyy, Yu.L. \& Boytsov, M.A. (eds) Kazus. Individual'noe $i$ unikal'noe v istorii [Casus. Individual and unique in history]. Moscow: Russian State University for the Humanities. pp. 17-41.

14. Radio Svoboda. (1999) Est' li budushchee u nauki o proshlom? (diskussiya po povodu stat'i M. Boytsova "Vpered, k Gerodotu!") [Is there a future for the science about the past? (Discussion on the article by M. Boytsov "Ahead, to Herodotus!")]. [Online] Available from: http://archive.svoboda.org/programs/td/1999/td.030399.asp. (Accessed: 25th March 2015).

15. Savchenko, A. (1996) Sem' let ryadom so L'vom Gumilevym [Seven years next to Lev Gumilev]. Novyy mir. 2. pp. 240-250.

16. Prusakov, D.B. (2010) Drevniy Egipet: pochva tsivilizatsii (Etyud o neoliticheskoy revolyutsii) [Ancient Egypt: The soil of civilization (An essay about of the Neolithic revolution)]. Moscow: LIBROKOM.

17. Kul'pin, E.S. (2001) Rus' mezhdu Zapadom i Vostokom [Rus between East and West]. Moscow: Institute for Oriental Studies RAS.

18. Viktorova, V.D. (1989) Nauchnyy poisk v arkheologii [Scientific research in archeology]. Sverdlovsk: Urals State University.

19. Volkov, P.V. (2009) Metodika tekhnologicheskogo issledovaniya i tipologii galechnykh artefaktov [Methods of technological research and typology of pebble artifacts]. Novosibirsk: Novosibirsk State University. 